\title{
Ehrlichia canis em cães atendidos em hospital veterinário de Botucatu, Estado de Sáo Paulo, Brasil
}

\author{
Ehrlichia canis in dogs attended in a veterinary hospital from Botucatu, São Paulo State, Brazil \\ Tatiana E. H. Ueno ${ }^{1 *}$; Daniel M. Aguiar²; Richard C. Pacheco ${ }^{3}$; Leonardo J. Richtzenhain ${ }^{3}$; \\ Márcio G. Ribeiro ${ }^{4}$; Antônio C. Paes ${ }^{4}$; Jane Megid ${ }^{4}$; Marcelo B. Labruna ${ }^{3}$ \\ ${ }^{1}$ Unidade de Pesquisa e Desenvolvimento de Mirassol, Agência Paulista de Tecnologia dos Agronegócios - APTA \\ ${ }^{2}$ Departamento de Clínica Médica Veterinária, Faculdade de Agronomia e Medicina Veterinária, \\ Universidade Federal de Mato Grosso - UFMT \\ ${ }^{3}$ Departamento de Medicina Veterinária Preventiva e Saúde Animal, Faculdade de Medicina Veterinária e Zootecnia, \\ Universidade de Sáo Paulo - USP \\ ${ }^{4}$ Departamento de Higiene Veterinária e Saúde Pública, Faculdade de Medicina Veterinária e Zootecnia, \\ Universidade Estadual Paulista - UNESP
}

Recebido em 23 de Setembro de 2008

Aceito em 24 de Julho de 2009

\section{Resumo}

O presente estudo investigou a etiologia da erliquiose monocítica canina em 70 cáes atendidos no Hospital Veterinário da Universidade Estadual Paulista, na cidade de Botucatu, durante 2001 e 2002. Os cães foram avaliados segundo achados clínicos, epidemiológicos e laboratoriais e pela amplificação parcial e sequenciamento do gene $d s b$ de Ehrlichia. DNA de Ehrlichia canis foi amplificado e sequenciado em 28 (40,0\%) cáes. Observou-se maior frequência de animais positivos com idade até 12 meses $(\mathrm{P}<0,05)$. Diarreia, apatia e anorexia foram os sinais clínicos mais frequentes observados em $55,2 \%(\mathrm{P}=0,05), 47,0 \%(\mathrm{P}>0,05)$ e $42,2 \%(\mathrm{P}>0,05)$ dos cáes $\mathrm{PCR}$ positivos, respectivamente. Vinte e cinco cáes com anemia $\left(<5,5 \times 10^{6}\right.$ eritrócitos. $\left.\mu \mathrm{L}^{-1}\right)$ e 8 com leucopenia $\left(<5,5 \times 10^{3}\right.$ leucócitos. $\left.\mu \mathrm{L}^{-1}\right)$ foram positivos na PCR, porém não apresentaram associaçáo estatística $(\mathrm{P}>0,05)$ frente à infecçáo por $E$. canis. Todos os 28 cáes positivos na PCR apresentaram trombocitopenia $\left(<175 \times 10^{3}\right.$ plaquetas. $\left.\mu \mathrm{L}^{-1} ; \mathrm{P}<0,05\right)$. E. canis foi a única espécie de Ehrlichia detectada em cáes da regiáo estudada, com alta taxa de infecção em cáes jovens e, estatisticamente, associada a cães trombocitopênicos.

Palavras-chave: Ehrlichia canis, PCR, Brasil, cães, erliquiose.

\begin{abstract}
This study investigated the etiology of canine ehrlichiosis and possible clinical and epidemiological data associated with the infection in 70 dogs suspect of ehrlichiosis attended at the Veterinary Hospital of the São Paulo State University in Botucatu city during 2001 and 2002. Dogs were evaluated by clinical-epidemiological and hematological data and molecular analysis by partial amplification and DNA sequencing of the ehrlichial $d s b$ gene. E. canis DNA was amplified and sequenced in $28(40.0 \%)$ dogs. Dogs younger than 12 months old showed significantly higher infection rates (65.0\%; $\mathrm{P}<0.05)$. Diarrhea, apathy, and anorexia were the major clinical signs observed in $55.2 \%(\mathrm{P}=0.05), 47.0 \%$ $(\mathrm{P}>0.05)$, and $42.4 \%(\mathrm{P}>0.05)$ of the PCR-positive dogs, respectively. Twenty-five anemic $\left(<5.5 \times 10^{6} \mathrm{RBC} \mu \mathrm{L}^{-1}\right)$, and 8 leukopenic $\left(<5.5 \times 10^{3} \mathrm{WBC}_{\mu} \mu \mathrm{L}^{-1}\right)$ dogs were PCR-positive $(\mathrm{P}>0.05)$. All $28 \mathrm{PCR}$-positive dogs showed thrombocytopenia $\left(<175 \times 10^{3}\right.$ platelets. $\left.\mu \mathrm{L}^{-1}\right)$ and revealed statistical significance $(\mathrm{P}<0.05)$. E. canis was the only Ehrlichia species found in dogs in the studied region, with higher infection rates in younger dogs, and statistically associated with thrombocytopenia.
\end{abstract}

Keywords: Ehrlichia canis, PCR, Brazil, dogs, ehrlichiosis.

\footnotetext{
*Autor para correspondência: Tatiana E. H. Ueno

Unidade de Pesquisa e Desenvolvimento de Mirassol,

Agência Paulista de Tecnologia dos Agronegócios - APTA,

Rod. Washigton Luiz, km 445, CP 1.013, CEP 15025-990,

São José do Rio Preto - SP, Brasil; e-mail: tatianaueno@apta.sp.gov.br

Telefone: +55 (17) 3233-1500
} 


\section{Introduçáo}

As erliquioses caninas figuram entre as mais graves doenças infecciosas que acometem os cáes, causadas por bactérias do gênero Ehrlichia, principalmente pela espécie Ehrlichia canis, agente etiológico da erliquiose monocítica canina (EMC) (DUMLER et al., 2001). A transmissão de E. canis ocorre durante o parasitismo por ninfas e/ou adultos do carrapato Rhipicephalus sanguineus, o qual mantém a bactéria por transmissão transestadial. Como não há transmissão transovariana de E. canis em carrapatos, as larvas de $R$. sanguineus não são importantes na transmissão, porém podem se infectar pelo agente, mantendo a infecção até o estágio adulto (GROVES et al., 1975; BREMER et al., 2005). No Brasil, as frequências de carrapatos $R$. sanguineus encontrados naturalmente infectados por $E$. canis têm variado de 2,3 a 6,2\% (AGUIAR et al., 2007). Não obstante, o parasitismo por $R$. sanguineus tem sido apontado como principal fator de risco para a EMC (TRAPP et al., 2006). Esse carrapato encontra-se preferencialmente em regióes urbanas do país, porém também em menores densidades nas áreas rurais (LABRUNA; PEREIRA, 2001; LABRUNA et al., 2001) e provavelmente, em todo o território nacional. Estudos epidemiológicos no Brasil têm revelado prevalências de EMC que variam de 4,8 a $65 \%$ em cáes de ambiente urbano ou rural (AGUIAR et al., 2007; COSTA Jr. et al., 2007; SAITO et al., 2008). Para cáes atendidos em clínicas e hospitais veterinários, a frequência de animais infectados tem oscilado entre 20 a 30\%, diagnosticada por testes sorológicos ou moleculares (BULLA et al., 2004; DAGNONE et al., 2003; LABARTHE et al., 2003; TRAPP et al., 2006).

A EMC geralmente apresenta um período de incubaçáo de 8 a 20 dias. A doença é caracterizada por manifestaçôes clínicas multissistêmicas, que variam na intensidade de acordo com as fases da doença, quais sejam: aguda, assintomática (subclínica) e crônica. Durante a fase aguda, os cáes infectados se recuperam espontaneamente, entrando numa fase assintomática ou subclínica, podendo permanecer infectados por longos períodos. Nesta fase, cáes imunocompetentes podem eliminar o parasita ou, ocasionalmente, desenvolvem a fase crônica da doença, caracterizada por supressão medular, sangramentos por mucosas e conjuntivas e alta letalidade (HARRUS et al., 1997).

O diagnóstico laboratorial de EMC tem sido rotineiramente realizado pela identificação direta de estruturas morfologicamente compatíveis com mórulas de E. canis em amostras de sangue periférico, aliada a exames hematológicos (NAKAGHI et al., 2008). Em anos recentes, com o objetivo de aumentar a sensibilidade e a especificidade do diagnóstico laboratorial direto, tem sido utilizada a detecção molecular de E. canis (DAGNONE et al., 2003; BULLA et al., 2004; MACIEIRA et al., 2005). Entretanto, na rotina clínica em animais de companhia, o diagnóstico ainda é firmado com base na associação entre os sinais clínicos e os resultados de exames hematológicos.

Diante da importância da EMC na rotina clínica veterinária, da alta casuística da doença em hospitais veterinários e na população canina, o presente estudo avaliou cães com sintomatologia compatível de erliquiose, atendidos em um hospital veterinário no município de Botucatu, Estado de São Paulo.

\section{Material e Métodos}

Este estudo avaliou 70 cáes, machos e fêmeas, com idades e raças variadas, atendidos entre 2001 e 2002 pelo Serviço de Doenças Infecciosas dos Animais, da Faculdade de Medicina Veterinária e Zootecnia, da UNESP/ Botucatu, SP. Os 70 cães tiveram diagnóstico clínico presuntivo de EMC, por apresentarem alguns dos sintomas clínicos descritos abaixo, os quais são relatados na literatura como compatíveis com EMC (GREENE, 2006): anorexia, hiporexia, apatia, prostração, diarreia, febre, vômito, hepato-esplenomegalia, linfoadenopatia, neuropatias, petéquias e sufusóes em mucosas e conjuntivas.

Durante o atendimento, foram obtidas amostras de sangue venoso em EDTA de cada cáo, sendo direcionadas para exames hematológicos e reação em cadeia pela polimerase (PCR), conforme descrito abaixo. Paralelamente, para cada amostra sanguínea, foi realizada a pesquisa de estruturas compatíveis com mórulas de $E$. canis no interior de leucócitos, através de esfregaços sanguíneos conforme previamente descrito (ELIAS, 1992). Durante a anamnese, foram obtidas informaçóes sobre as seguintes variáveis epidemiológicas relacionadas ao cáo: área de moradia (rural ou urbana), acesso a ruas, dieta (ração comercial ou caseira) e histórico de infestação por carrapatos nos últimos 90 dias. Os carrapatos presentes nos cães no momento do atendimento clínico foram colhidos e identificados conforme a espécie, segundo Aragáo e Fonseca (1961).

Os exames hematológicos foram realizados conforme Jain (2000) e Kaneko (1997), para identificar animais com anemia, leucopenia e/ou trombocitopênicos, sugestivos da doença em fase aguda ou crônica. Foram considerados anêmicos, leucopênicos e trombocitopênicos os animais que apresentaram, respectivamente, valores inferiores a $5,5 \times 10^{6} . \mu \mathrm{L}^{-1}$ hemácias, 5.500. $\mu \mathrm{L}^{-1}$ leucócitos e $175.000 . \mu \mathrm{L}^{-1}$ plaquetas.

A PCR foi realizada conforme Doyle et al. (2005), visando à amplificação de fragmento de 409 pares de base $(\mathrm{pb})$ do gene $d s b$ de Ehrlichia spp., utilizando-se os iniciadores Dsb-330 (5'-GAT GAT GTC TGA AGA TAT GAA ACA AAT-3') e Dsb-728 (CTG CTC GTC TAT TTT ACT TCT TAA AGT-3'). As amostras com fragmentos amplificados de $409 \mathrm{pb}$ foram submetidas ao sequenciamento de nucleotídeos em sequenciador automático de DNA (ABI Prism 310 Genetic Analyser - Applied Biosystens/Perkin Elmer), conforme instruções do fabricante. As sequências obtidas foram comparadas pelo Blast Analysis com outras sequências de Ehrlichia spp. disponíveis no GenBank, utilizando-se o programa MegAlign do pacote Lasergene R versão 8.0 para windows (DNASTAR, EUA).

A avaliação estatística dos resultados foi realizada com base na associação entre os achados clínicos, exames laboratoriais, variáveis epidemiológicas e PCR. Foi considerada a variável dicotômica denominada resultado, que assumiu o valor 1 nos cáes caracterizados como positivos na PCR e 0 , se negativo. Calculou-se como medida de associaçáo o teste do Qui-quadrado $\left(\chi^{2}\right)$, e exato de Fischer, ambos com intervalo de confiança de $95 \%$. O teste Kappa foi realizado para avaliar a concordância entre o diagnóstico por meio da detecção de mórulas em esfregaços sanguíneos e a PCR. Para fins de cálculo estatístico, os animais estudados foram divididos entre as idades de 1 a 12 meses, $>12$ a 48 meses e acima de 48 meses. 


\section{Resultados}

Dos 70 cães avaliados, em 28 (40,0\%) foi constatada a presença de DNA compatível com o gênero Ehrlichia no sangue periférico, pela PCR. Após o sequênciamento de DNA dos 28 produtos amplificados, foram obtidos fragmentos de 355 nucleotídeos de cada produto (excluídas as porçóes correspondentes aos iniciadores), as quais mostraram-se idênticas entre si. Quando comparadas com as sequências de DNA disponíveis no GenBank, apresentaram-se 100\% similares aos isolados brasileiros Jaboticabal (DQ460716) e São Paulo (DQ460715) de E. canis e ao isolado Jake (AF403710) de E. canis dos Estados Unidos.

Com relação às variáveis epidemiológicas, 52 cães $(74,3 \%)$ eram de área urbana, 30 (42,9\%) tinham acesso à rua, 24 (34,3\%) consumiam dieta composta exclusivamente por raçáo comercial e $61(87,1 \%)$ possuíam histórico de presença de carrapatos nos últimos 90 dias. No momento do atendimento, 37 (52,9\%) cães tinham carrapatos, sendo todos identificados como $R$. sanguineus, exceto um cão que estava infestado por Rhipicephalus (Boophilus) microplus. Nenhuma dessas variáveis epidemiológicas mostrou associação significante $(\mathrm{P}>0,05)$ com a positividade pela PCR.

No tocante aos sintomas clínicos, foram observados nos 70 cães: anorexia ou hiporexia em 59 (84,2\%) cães; apatia ou prostração em 49 (70,0\%); diarreia em 29 (41,4\%); vômito em 26 (37,1\%); linfoadenopatia em 59 (84,2\%); esplenomegalia em 26 (37,1\%); sinais neurológicos em 17 (24,2\%); e hemorragias em $45(64,2 \%)$ cães.

Os resultados do teste do $\chi^{2}$ revelaram maior frequência de animais positivos com idade até 12 meses $(\mathrm{P}<0,05$; Tabela 1$)$. Dentre os sintomas apresentados pelos animais, somente a presença de diarreia mostrou associação significativa $(P=0,05)$, em que 16 (55,2\%) dos 29 cáes com diarreia foram positivos pela PCR. Dos 45 cães com hemorragias, 16 (35,5\%) foram positivos pela PCR (P > 0,05). Nas análises dos exames hematológicos, a variável trombocitopenia (plaquetas $<175.000$ ) foi a única que apresentou associação estatisticamente significante com a positividade pela PCR (Tabela 2). O teste Kappa apresentou baixa concordância entre a presença de mórulas em esfregaços sanguíneos (7,1\%; 5 cães positivos dos 70 testados) e a PCR $($ Kappa = 0,138 (IC 95\%: 0,02-0,296), Concordância = 0,643, erro padrão de 0,081$)$.

\section{Discussão}

A EMC é reconhecida como uma das principais doenças infecciosas na clínica de pequenos animais, notadamente pela ampla disseminação do carrapato $R$. sanguineus em todo Brasil. No presente estudo, 40\% (28/70) dos cães atendidos com manifestaçóes clínicas sugestivas de erliquiose continham DNA de E. canis em seu sangue total. Esse resultado encontra-se dentro do identificado em estudos similares conduzidos no Brasil (18 a 53\%), que também utilizaram a PCR no diagnóstico da erliquiose em cães encaminhados a hospitais veterinários (DAGNONE et al., 2003; BULLA et al., 2004; MACIEIRA et al., 2005; SANTOS et al., 2009; NAKAGHI at al., 2008).
Os resultados do presente estudo corroboram os resultados descritos por Bulla et al. (2004) e Diniz et al., (2007), na mesma região, nos quais a $E$. canis parece ser a única espécie desse gênero, infectando cães. A região objeto do estudo é considerada endêmica para a doença, visto que propicia condiçóes edafoclimáticas para a manutenção do vetor, no que se traduz a co-existência de cães infectados (fonte de infecção para carrapatos) e alta prevalência do carrapato vetor, como constatado no presente trabalho.

Dos 70 cães amostrados, apenas cinco $(7,1 \%)$ apresentaram mórulas em células mononucleares nos esfregaços sanguíneos, sendo que um deles foi negativo pela PCR, indicando um resultado falso positivo pelo exame de esfregaço sanguíneo. Apesar da facilidade de execução, baixo custo e rapidez dos resultados, classicamente este exame tem apresentado baixa sensibilidade e relativa baixa especificidade, decorrente provavelmente da flutuação parasitêmica do micro-organismo e da possibilidade de encontrar outras inclusões intracitoplasmáticas não relacionadas a $E$. canis (ELIAS, 1992). Contrariamente, a PCR tem demonstrado alta sensibilidade e especificidade em animais infectados, mesmo em baixas concentraçóes do micro-organismo na circulação sanguínea (McBRIDE et al., 1996).

O protocolo de PCR utilizado nos animais estudados tem sido empregado para a pesquisa de Ehrlichia spp. em animais e carrapatos (NDIP et al., 2005; AGUIAR et al., 2007; LABRUNA et al., 2007). A amplificação do gene $d s b$ tem revelado alta sensibilidade e especificidade, visto que os iniciadores utilizados (Dsb-330 e 728) detectam somente espécies do gênero Ehrlichia, ainda que realizada em uma única reação de amplificação (DOYLE et al., 2005).

Como o método de análise foi baseado na pesquisa direta de Ehrlichia spp. na circulação sanguínea, sugere-se que os cães positivos estivessem em fase aguda da doença ou num processo de recrudescência da doença durante a fase crônica. A maior frequência (65\%) da infecção constatada em cães com idade até 12 meses indica maior risco dos animais, nessa faixa etária, de contraírem a infecção e apresentarem o agente circulante, decorrentes de uma alta contaminação ambiental por carrapatos, que ocasiona exposição ao agente ainda nos primeiros meses de vida. Esses cães jovens possivelmente se apresentavam na fase aguda da doença. Por outro lado, os cães acima de 12 meses que foram positivos na PCR possivelmente correspondiam, em sua maioria, à recrudescência da infecção na fase crônica.

A presença de carrapatos nos cães não foi associada estatisticamente à infecçáo por $E$. canis nos animais amostrados. Tal fato possivelmente ocorreu porque quase todos os cães $(87,1 \%)$ apresentavam histórico de infestaçáo recente por carrapatos, incluindo 25 dos 28 cães positivos na PCR. Entretanto, $R$. sanguineus permanece como o principal transmissor e fator de risco para a infecção por $E$. canis em cães no Brasil (TRAPP et al., 2006; AGUIAR et al., 2007), fato reforçado em estudo recente que relatou a ausência de $E$. canis infectando outras espécies de carrapatos no Brasil (LABRUNA et al., 2007).

É interessante notar que a presença de diarreia foi associada estatisticamente no limítrofe $(\mathrm{P}=0,05)$ com a infecção por E. canis. No entanto, esse achado não tem sido apontado como sinal clínico frequente de erliquiose em cães (GREENE, 2006). Os sinais clínicos comumente observados no curso da infecção geralmente são inespecíficos (apatia, anorexia, emagrecimento, 
Tabela 1. Frequência de cães positivos pela reação em cadeia da polimerase para Ehrlichia canis, segundo faixa etária e sexo, em cães suspeitos de erliquiose atendidos no Serviço de Doenças Infecciosas dos Animais, da Faculdade de Medicina Veterinária e Zootecnia, da UNESP/ Botucatu, SP. Botucatu, SP, 2008.

\begin{tabular}{cccr}
\hline \multirow{2}{*}{$\begin{array}{c}\text { Idade } \\
\text { (meses) }\end{array}$} & \multicolumn{2}{c}{ Número de cáes positivos/ número de cães testados (\% positivos) } \\
\cline { 2 - 4 } & Machos & Fêmeas & Total \\
\hline 1 a 12 & $6 / 10(60,0)$ & $7 / 10(70,0)$ & $13 / 20(65,0)^{\mathrm{a}}$ \\
$>12$ a 48 & $7 / 20(35,0)$ & $3 / 11(27,3)$ & $10 / 31(32,3)^{\mathrm{b}}$ \\
>48 & $3 / 6(50,0)$ & $2 / 7(28,5)$ & $5 / 13(38,5)^{\mathrm{b}}$ \\
Não determinada & $2 / 3(66,6)$ & $1 / 3(33,3)$ & $3 / 06(50,0)$ \\
Total & $18 / 39(46,1)^{\mathrm{d}}$ & $13 / 31(42,0)^{\mathrm{d}}$ & $31 / 70(44,3)$ \\
\hline
\end{tabular}

*Letras diferentes na mesma linha ou coluna indicam $\mathrm{P}<0,05$.

Tabela 2. Associaçáo entre achados dos exames hematológicos e resultados da reação em cadeia da polimerase (PCR), em cães com suspeita clínica de erliquiose atendidos no Serviço de Doenças Infecciosas dos Animais, da Faculdade de Medicina Veterinária e Zootecnia, da UNESP/ Botucatu, SP.

\begin{tabular}{|c|c|c|c|c|c|}
\hline \multirow{2}{*}{$\begin{array}{c}\text { Exames } \\
\text { hematológicos }\end{array}$} & \multicolumn{3}{|c|}{ Cáes } & \multirow{2}{*}{$\chi^{2}$} & \multirow{2}{*}{$\mathbf{P}$} \\
\hline & $\mathbf{n}$ & PCR Positivos & $\%$ & & \\
\hline \multicolumn{6}{|l|}{ VG } \\
\hline$\geq 37,0$ & 17 & 6 & 35,3 & \multirow{2}{*}{0,029} & \multirow{2}{*}{0,86} \\
\hline$<37,0$ & 53 & 22 & 41,5 & & \\
\hline \multicolumn{6}{|l|}{ Hemácias } \\
\hline$\geq 5.500$ & 10 & 3 & 30,0 & \multirow{2}{*}{0,440} & \multirow{2}{*}{0,22} \\
\hline$<5.500$ & 60 & 25 & 41,7 & & \\
\hline \multicolumn{6}{|l|}{ Hemoglobina } \\
\hline$\geq 12$ & 20 & 7 & 35,0 & \multirow{2}{*}{0,072} & \multirow{2}{*}{0,78} \\
\hline$<12$ & 50 & 21 & 42,0 & & \\
\hline \multicolumn{6}{|l|}{ Leucócitos } \\
\hline$<5.500$ & 25 & 8 & 32,0 & \multirow{3}{*}{3,20} & \multirow{3}{*}{0,20} \\
\hline $5.500-16.900$ & 42 & 20 & 47,6 & & \\
\hline$>16.900$ & 3 & 0 & 0 & & \\
\hline \multicolumn{6}{|l|}{ Segmentados } \\
\hline$<3.000$ & 14 & 4 & 28,6 & \multirow{3}{*}{5,00} & \multirow{3}{*}{0,08} \\
\hline $3.000-12.000$ & 47 & 24 & 51,0 & & \\
\hline$>12.000$ & 4 & 0 & 0 & & \\
\hline \multicolumn{6}{|l|}{ Linfócitos } \\
\hline$<1000$ & 39 & 19 & 48,7 & \multirow{3}{*}{1,70} & \multirow{3}{*}{0,42} \\
\hline $1.000-4.900$ & 25 & 9 & 36,0 & & \\
\hline$>4.900$ & 1 & 0 & 0 & & \\
\hline \multicolumn{6}{|l|}{ Monócitos } \\
\hline$<100$ & 7 & 1 & 14,3 & \multirow{3}{*}{2,65} & \multirow{3}{*}{0,26} \\
\hline $100-1.400$ & 53 & 25 & 47,2 & & \\
\hline$>1.400$ & 5 & 2 & 40,0 & & \\
\hline \multicolumn{6}{|l|}{ Eosinófilos } \\
\hline$<100$ & 43 & 21 & 48,8 & \multirow{3}{*}{1,77} & \multirow{3}{*}{0,41} \\
\hline $100-1490$ & 19 & 6 & 31,6 & & \\
\hline$>1490$ & 3 & 1 & 33,3 & & \\
\hline Plaquetas & & & & & \\
\hline$\geq 175.000$ & 6 & 0 & 0 & 437 & 004 \\
\hline$<175.000$ & 64 & 28 & 43,8 & 4,32 & 0,04 \\
\hline Mórula & & & & & \\
\hline Não & 65 & 24 & 37,0 & 340 & 0.07 \\
\hline Sim & 5 & 4 & 80,0 & 3,40 & 0,07 \\
\hline
\end{tabular}

febre e linfoadenopatias) e não apresentaram associação com a presença de $E$. canis nos animais, o que reforça a importância da associação dos achados clínico-epidemiológicos e laboratoriais, com vistas a incrementar o diagnóstico da enfermidade.

A hemorragia, caracterizada como distúrbio associado à EMC (FRANK; BREITSCHWERDT, 1999), apresentou altas frequências entre os cães com resultados PCR negativos. Os cães em estágios crônicos da doença apresentam com mais frequência distúrbios vasculares que, geralmente, são associados a quadros mais intensos de trombocitopenia, mais característicos nesta fase. Por outro lado, postula-se que, na fase assintomática ou subclínica (estágios de cronicidade), os cães podem se apresentar negativos na PCR do sangue periférico, visto que, nessa fase, o agente encontra-se presente no baço, em detrimento da circulação sanguínea (HARRUS et al., 1998), o que justificaria a baixa eficiência na PCR nessa categoria dos animais testados.

Cães trombocitopênicos $\left(<175.000\right.$ plaquetas. $\left.\mu \mathrm{L}^{-1}\right)$ revelaram associação estatística significante $(\mathrm{P}<0,05)$ na $\mathrm{PCR}$ de $E$. canis da circulação sanguínea. Esse resultado está em concordância com estudos similares no Brasil, que também têm assinalado a trombocitopenia como achado frequente nas infecçôes por $E$. canis (BULLA et al., 2004; DAGNONE et al., 2003; MACIEIRA et al., 2005; NAKAGHI et al., 2008). No entanto, Anaplasma platys e Babesia canis também podem acarretar trombocitopenia em cáes (MACIEIRA et al., 2005), o que reforça a necessidade do diagnóstico desses hemoparasitas e de outras causas de diminuição de plaquetas em cães.

O presente estudo ratifica a espécie $E$. canis como agente responsável pela EMC na regiāo de Botucatu, Estado de São Paulo. Nessa região, a alta contaminação ambiental por carrapatos, associada à alta frequência de cáes infectados, têm permitido a primo-infecção ainda nos primeiros meses de vida dos cães.

\section{Agradecimentos}

À Fundação de Amparo a Pesquisa do Estado de São Paulo, pelos recursos destinados a este estudo e pela bolsa de RCP. Ao Conselho Nacional de Desenvolvimento Científico e Tecnológico (CNPq), pela concessão de bolsa de produtividade científica à MBL e MGR. 


\section{Referências}

AGUIAR, D. M. et al. Prevalence of Ehrlichia canis (Rickettsiales: Anaplasmataceae) in dogs and Rhipicephalus sanguineus (Acari: Ixodidae) ticks from Brazil. Journal of Medical Entomology, v. 44, n. 1, p. 126-132, 2007.

ARAGÃO, H.; FONSECA, F. Notas de Ixodologia. VII Lista e chave para os representantes da fauna ixodológica brasileira. Memórias do Instituto Oswaldo Cruz, v. 59, n. 2, p. 115-129, 1961.

BREMER, W. G. et al. Transstadial and intrastadial experimental transmission of Ehrlichia canis by male Rhipicephalus sanguineus. Veterinary Parasitology, v. 131, n. 1-2, p. 95-105, 2005.

BULLA, C. et al. The relationship between the degree of thrombocytopenia and infection with Ehrlichia canis in an endemic area. Veterinary Research, v. 35, n. 1, p. 141-146, 2004.

COSTA, L. M. J. R. et al. Sero-prevalence and risk indicators for canine ehrlichiosis in three rural areas of Brazil. The Veterinary Journal, v. 174, n. 3, p. 673-6, 2007.

DAGNONE, A. S. et al. Ehrlichiosis in anemic, thrombocytopenic, or tick-infested dogs from a hospital population in south Brazil. Veterinary Parasitology, v. 117, n. 4, p. 285-290, 2003.

DINIZ, P. P. V. P. Surveillance for zoonotic vector-borne infections using sick dogs from southeastern Brazil. Vector Borne and Zoonotic Diseases, v. 7, n. 4, p. 689-97, 2007.

DOYLE, C. K. et al. Detection of medically important Ehrlichia by Quantitative Multicolor TaqMan Real-time polymerase chain reaction of the $d s b$ Gene. Journal of Molecular Diagnostics, v. 7, n. 4, p. 504-510, 2005.

DUMLER, J. S. et al. Reorganization of genera in the families Rickettsiaceae and Anaplasmataceae in the order Rickettsiales: unification of some species of Ehrlichia with Anaplasma, Cowdria with Ehrlichia and Ehrlichia with Neorickettsia, descriptions of six new species combinations and designation of Ehrlichia equi and HGE agent as subjective synonyms of Ehrlichia phagocytophila. International Journal of Systematic and Evolutionary Microbiology, v. 51, n. 6, p. 2145-2165, 2001.

ELIAS, E. Diagnosis of ehrlichiosis from the presence of inclusion bodies or morulae of E. canis. Journal of Small Animal Practice, v. 33, n. 11, p. 540-543, 1992.

FRANK, J. R.; BREITSCHWERDT, E. B. A retrospective study of ehrlichiosis in 62 dogs from North Carolina and Virginia. Journal of Veterinary Internal Medicine, v. 13, n. 3, p. 194-201, 1999.

GREENE, C. E. Infectious diseases of the dog and cat. 3 ed. Philadelphia: Elsevier B.V. Saunders Company, 2006. 1424 p.

GROVES, M. G. et al. Transmission of Ehrlichia canis to dogs by ticks (Rhipicephalus sanguineus). American Journal of Veterinary Research, v. 36, n. 7, p. 937-940, 1975.
HARRUS, S. et al. Amplification of ehrlichial DNA from dogs 34 months after infection with Ehrlichia canis. Journal of Clinical Microbiology, v. 36, n. 1, p. 73-76, 1998.

HARRUS, S.; WANER, T.; BARK, H. Canine monocytic ehrlichiosis: an update. Compendium on Continuing Education for the Practicing Veterinarian, v. 19, n. 4, p. 431-444, 1997.

JAIN, N. C. Schalm's Veterinary Hematology. 5 ed. Philadelphia: Williams and Wilkins, 2000. 1344 p.

KANEKO, J. J. Serum proteins and dysproteinemias. In: KANEKO, J. J.; HARVEY, J. W.; BRUSS, M. L. Clinical biochemistry of domestic animals. 5 ed. San Diego: Academic Press, 1997. p. 117-138.

LABARTHE N. et al. Serologic prevalence of Dirofilaria immintis, Ehrlichia canis and Borrelia burgdorferi infection in Brazil. Veterinary Therapeutics, v. 4, p. 67-75, 2003.

LABRUNA, M. B.; PEREIRA, M. C. Carrapatos em cães no Brasil. Clinica Veterinária, v. 30, n. 1, p. 24-32, 2001.

LABRUNA, M. B. et al. Prevalência de carrapatos em cáes de áreas rurais da região norte do Estado do Paraná. Arquivo Brasileiro de Medicina Veterinária e Zootecnia, v. 53, n. 5, p. 553-556, 2001.

LABRUNA, M. B. et al. A preliminary investigation of Ehrlichia species in ticks, humans, dogs, and capybaras from Brazil. Veterinary Parasitology, v. 143, n. 2, p. 189-95, 2007.

MACIEIRA, D. B. et al. Prevalence of Ehrlichia canis infection in thrombocytopenic dogs from Rio de Janeiro, Brazil. Veterinary Clinical Pathology, v. 34, n. 1, p. 44-8, 2005.

McBRIDE, J. W. et al. PCR detection of acute Ehrlichia canis infection in dogs. Journal of Veterinary Diagnostic Investigation, v. 8, n. 4 , p. 441-447, 1996.

NAKAGHI, A. C. H. et al. Canine ehrlichiosis: clinical, hematological, serological and molecular aspects. Ciência Rural, v. 38, n. 3, p. 766-770, 2008.

NDIP, L. M. et al. Ehrlichial infection in Cameroonian canines by Ehrlichia canis and Ehrlichia ewingii. Veterinary Microbiology, v. 111, n. 1-2, p. 59-66, 2005.

SAITO, T. B. et al. Canine Infection by Rickettsiae and Ehrlichiae in Southern Brazil. American Journal of Tropical Medicine and Hygiene, v. 79, n. 1, p. 102-108, 2008.

SANTOS, F. et al. Molecular evaluation of the incidence of Ehrlichia canis, Anaplasma platys and Babesia spp. in dogs from Ribeirão Preto, Brazil. Veterinary Journal, v. 179, n. 1, p. 145-148, 2009.

TRAPP, S. M. et al. Seroepidemiology of canine babesiosis and ehrlichiosis in a Hospital population. Veterinary Parasitology, v. 140, n. 3-4, p. 223-230, 2006. 